\title{
A Review on Structure, Modifications and Structure-Activity Relation of Quercetin and Its Derivatives
}

\author{
Rubin Thapa Magar ${ }^{1}$ and Jae Kyung Sohng ${ }^{1,2 *}$ \\ ${ }^{1}$ Department of Life Science and Biochemical Engineering, SunMoon University, Asan 31460, Republic of Korea \\ ${ }^{2}$ Department of Pharmaceutical Engineering and Biotechnology, SunMoon University, Asan 31460, Republic of Korea
}

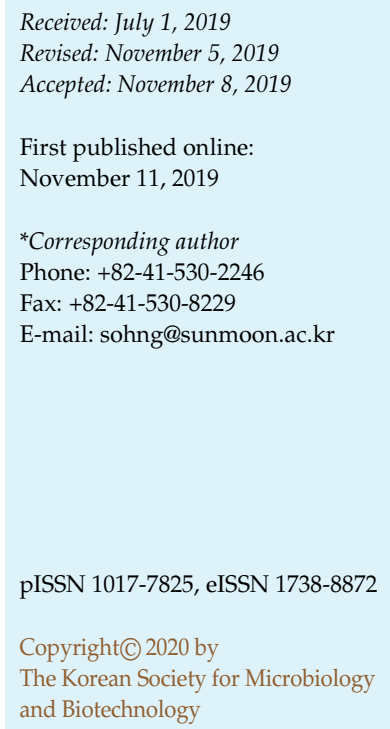

\begin{abstract}
Quercetin and its derivatives are important metabolites that belong to the flavonol class of flavonoids. Quercetin and some of the conjugates have been approved by the FDA for human use. They are widely distributed among plants and have various biological activities, such as being anticancer, antiviral, and antioxidant. Hence, the biosynthesis of novel derivatives is an important field of research. Glycosylation and methylation are two important modification strategies that have long been used and have resulted in many novel metabolites that are not present in natural sources. A strategy for modifying quercetin in E. coli by means of glycosylation, for example, involves overexpressing respective glycosyltransferases (GTs) in the host and metabolic engineering for increasing nucleoside diphosphate sugar (NDP-sugar). Still others have used microorganisms other than E. coli, such as Streptomyces sp., for the biotransformation process. The overall study of the structural activity relationship has revealed that modification of some residues in quercetin decreased one activity but increased others. This review summarizes all of the information mentioned above.
\end{abstract}

Keywords: Quercetin, glycosylation, methylation, biotransformation

\section{Introduction}

Quercetin is one of the important flavonoids that belongs to the flavonol class of flavonoids and are distributed widely among the fruits and vegetables, such as onion [1] and mango [2]. Plants contain not only aglycone (quercetin) but also the various types of conjugated forms of quercetin with glycosides as well as methyl ethers. One of the important derivatives, isoquercetin, also known as isoquercetrin or isotrifolin is found to be present in onions [1] and mangoes [2]. Other important derivatives includes rutin which is available mainly in citrus foods.

Quercetin and its derivatives are pharmacologically active compounds, because they show various biological activities. Quercetin has an anticancer activity as an inhibitor of human cathepsin B [3]. Many others derivatives have antiviral activities; for example, quercetin 3-O- $\beta$-D-glucoside (Isoquercetrin) works against ebola virus [4]. There are other methylated derivatives that have different activities. As for example, rhamnetin (7-O-methyl quercetin) has an anti-inflammatory effect [5].

Enzymatically modified isoquercitrin (EMIQ) is another major quercetin derivatives with significant applications. It is more beneficial than rutin because it is highly water soluble and more easily absorbed than other quercetin glycosides and quercetin itself [6]. It has been granted approval as a food additive in Japan and is generally regarded as safe (GRAS) safe as an antioxidant by the U.S. FDA. It has been used as a dietary supplement as bioactive quercetin.

\section{Structure of Quercetin and Its Derivatives}

Quercetin (2-(3,4-dihydroxyphenyl)-3,5,7-trihydroxy-4Hchromen-4-one), a major class of flavonoids, contains five hydroxyl groups at $3,5,7,3^{\prime}$ and $4^{\prime}$ of the basic skeleton of flavonol. Some of these hydroxyl groups are glycosylated to various quercetin glycosides and constitute the major quercetin derivatives.

Structurally, isoquercetin contains glucose attached to the 
3-OH group of quercetin. Moreover, galactose attachment to the $3-\mathrm{OH}$ of quercetin leads to the synthesis of hyperoside (quercetin 3-O-galactoside). Similarly, the rhamnosyl group also attaches to $3-\mathrm{OH}$ or $7-\mathrm{OH}$ and leads to the synthesis of quercetin 3-O-rhamnoside and quercetin 7-O-rhamnoside, respectively.

Some quercetin derivatives also contain disaccharides, such as rutinose, which is composed of rhamnose and glucose group and is named $\alpha$-L-rhamnopyranosyl-(1 $\rightarrow 6)$ $\beta$-D-glucopyranose. Attachment of this disaccharide at the $3-\mathrm{OH}$ position of quercetin leads to the important compound named rutin. Likewise, avicularin contains the arabinofuranose attached to quercetin 3-OH.

Some quercetin derivatives have more than two sugar residues as well. Examples include enzymatically modified isoquercetrin (EMIQ) and oligoglucosylated rutin. The former contains up to 10 glucose residues attached to the 3$\mathrm{OH}$ of quercetin, whereas the latter contain up to five more glucose residues attached to the glucose residue of rutin.

There are also some methylated quercetin derivatives. For example, tamrixetin, quercetin $4^{\prime}$-methyl ether, contains an extra methyl group at the $4^{\prime}$ position of quercetin. Similarly, another methylated quercetin, rhamnetin 7-Omethyl quercetin has a methyl group at $7-\mathrm{OH}$ of quercetin. Moreover, dimethylated quercetin, named rhamnazin, contains two methyl groups at the $3^{\prime}$ - and $7-\mathrm{OH}$ groups of quercetin. Isorhamnetin is another methylated flavonol, also known as 3-methylquercetin and isorhamnetol. It can be glycosylated to form isorhamnetin 3-O-rutinoside (narcissin), isorhamnetin 3-O-rutinoside-7-O-glucoside, and isorhamnetin 3-O-rutinoside-4'-O-glucoside.

There are more structural diversities in quercetin that contains both the glycosyl group and methyl groups attached to $\mathrm{OH}$ groups of quercetin. For example, tamarixetin 3-O- $\beta$-D-glucoside contains a methyl group at the $4^{\prime}$ position and glucose at the 3 position. Structures of some of the selected quercetin conjugates are given in Fig. 1.

\section{Approaches for Quercetin Modifications}

Quercetin derivatives have various biological activities. Hence, the modification of quercetin has been extensively studied in the field of flavonoids research in order to generate various quercetin derivatives with diverse structures and functions. Biotransformation is an important tool for the modification of quercetin, where the microorganisms are engineered to express the desired biocatalysts that do the desired modification, such as glycosylations or methylations. For these desired modification processes, most researchers use metabolically engineered E. coli strain, and others use microorganisms such as Streptomyces sps. Moreover, in vitro modification with purified biocatalysts is another tool for synthesis of quercetin derivatives.

\section{In Vitro Modification of Quercetin}

Glycosylation. There are various instances where the purified biocatalysts are used for the modification of quercetin. All the biocatalysts are overexpressed, purified and used for the modification of quercetin. In one example, the in vitro synthesis of two novel quercetin sialyllactoside derivatives, quercetin-3-O- $\beta$-D-glucopyranosyl, 4"-O-Dgalactopyranosyl $3^{\prime \prime \prime}-O-\alpha-N$-acetyl neuraminic acid, i.e., 3 'sialyllactosyl quercetin ( $\left.3^{\prime}-\mathrm{SL}-\mathrm{Q}\right)$ and quercetin-3-O- $\beta-\mathrm{D}-$ glucopyranosyl, $\quad 4^{\prime \prime}-O-\beta$-D-galactopyranosyl $\quad 6^{\prime \prime \prime}-O-\alpha-N-$ acetylneuraminic acid, i.e., 6'-sialyllactosyl quercetin (6'SL-Q) was performed [7]. They used glucosyltransferase UGT78K1 (Glycine max), $\beta$-1,4-galactosyltransferase (Helicobacter pylori), and two different sialyltransferases, $\alpha 2,3-$ SiaT and $\alpha 2,6-$ SiaT. At first, they synthesize the quercetin-3-O- $\beta$-D-glucoside (QG) by using a one-pot reaction system having a crude enzyme UMK (UMP kinase), ACK (acetate kinase), GalU (UDP- $\alpha$-D-glucose synthase), and UGT78K1 (glycosyltransferase). More than $90 \%$ conversion was seen. Then, they converted QG to quercetin 3-O- $\beta$-Dlactoside (QL) by using QG as the substrate and $\beta-1,4-$ galactosyltransferase as GT to achieve more than $95 \%$ conversion. Finally, the desired products were formed by using QL as the substrate and $\alpha 2,3-$ SiaT and $\alpha 2,6-$ SiaT as sialyltransferases. The conversion rate was almost $95 \%$. This is summarized in Fig. 2.

Production of EMIQ from rutin. It is an important method for the modification of rutin to important derivatives like EMIQ (enzyme modified isoquercetrin). Unlike all other methods described above, glycosidase acts as the most important enzyme in this modification strategy.

Rutin to isoquercetrin (IQ): Isoquercetrin is an important quercetin derivative, because it is the substrate for another important quercetin derivative known as EMIQ and has various biological activities as well. Several methods have been used for the synthesis of this compounds. $\alpha$-Lrhamnosidases is an enzyme that can hydrolyze the rhamnosyl group of rutin to produce isoquercetrin. There are several pieces of evidence of isoquercetrin production from rutin using rhamnosidase enzymes. In one evidence, it was produced by using the naringinase (EC 3.2.1.40) from Penicillium decumbens [8]. In this case, a maximum 


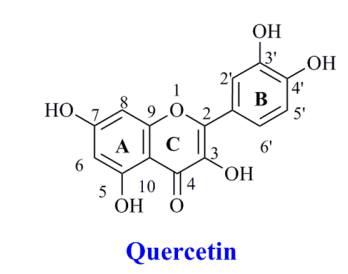

3-O Glycosides<smiles>O=c1c(OC2OC3C(O)C(O)C(O)C(O)C3O2)c(-c2ccc(O)c(O)c2)oc2cc(O)cc(O)c12</smiles>

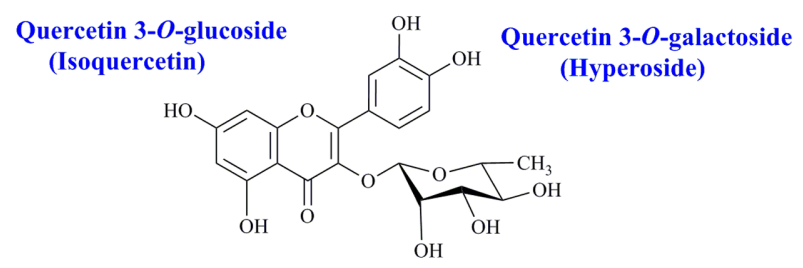

Quercetin 3-O-rhamnoside (Quercetrin)

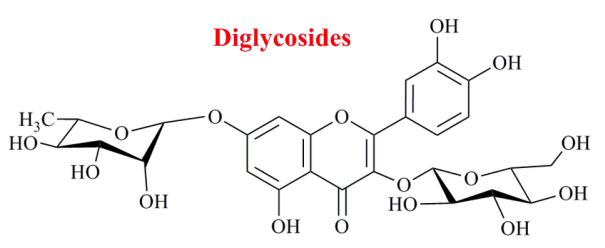

Quercetin 3-O-glucoside 7-O-rhamnoside

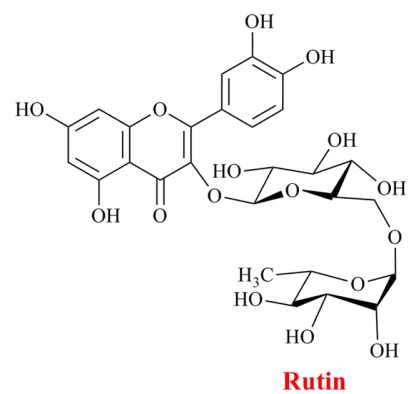<smiles>COc1ccc(-c2oc3cc(O)cc(O)c3c(=O)c2O)cc1O</smiles>

4'-O-methoxy quercetin (Tamarixetin)<smiles>COc1ccc(-c2oc3cc(OC)cc(O)c3c(=O)c2O)cc1</smiles>

7'-O-methoxy quercetin (Rhamnetin)

Polyglycosides
Modifications of quercetin in

\begin{tabular}{|c|c|c|c|}
\hline Derivatives & Ring A & Ring B & Ring C \\
\hline $\begin{array}{l}\text { Quercetin 3-O-glucoside } \\
\text { (isoquercetrin) }\end{array}$ & $\mathbf{X}$ & $\mathbf{X}$ & 3-OH to 3-O-glucoside \\
\hline $\begin{array}{l}\text { Quercetin 3-O-galactoside } \\
\text { (hyperoside) }\end{array}$ & $\mathbf{X}$ & $\mathbf{X}$ & 3-OH to 3- $O$-galactoside \\
\hline $\begin{array}{l}\text { Quercetin 3-O-rhamnoside } \\
\text { (Quercitrin) }\end{array}$ & $\mathbf{X}$ & $\mathbf{X}$ & 3-OH to 3-O-rhamnoside \\
\hline Quercetin 7-O-glucoside & $\begin{array}{l}\text { 7-OH to } \\
\text { 7-O-glucoside }\end{array}$ & $\mathbf{X}$ & $\mathbf{X}$ \\
\hline $\begin{array}{l}\text { Quercetin 3-O-rutinoside } \\
\text { (rutin) }\end{array}$ & $\mathbf{X}$ & $\mathbf{X}$ & 3-OH to 3-O-rutinoside \\
\hline $\begin{array}{l}\text { Quercetin 3-methyl ether } \\
\text { (Isorhamnetin) }\end{array}$ & $\mathbf{X}$ & $\mathbf{X}$ & $3-\mathrm{OH}$ to $3-O$-methyl ether \\
\hline Quercetin 3,3'-dimethyl ether & $3^{\prime}-C$ & $\begin{array}{l}\text { 3'-OH to } \\
O \text {-methyl ether }\end{array}$ & $3-\mathrm{OH}$ to $3-O$-methyl ether \\
\hline $\begin{array}{l}\text { Quercetin-4'-glucoside } \\
\text { Spiraeoside }\end{array}$ & $\mathbf{X}$ & $\begin{array}{l}\text { 4'-OH to } \\
\text { 4'-O-glucoside }\end{array}$ & $\mathbf{X}$ \\
\hline
\end{tabular}

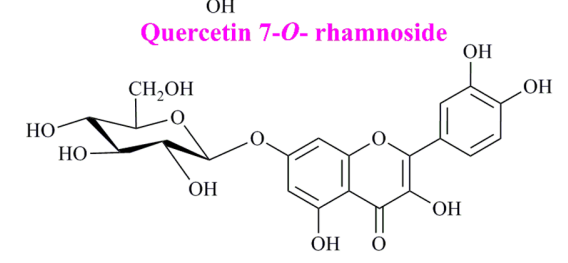

Quercetin 7-O-glucoside

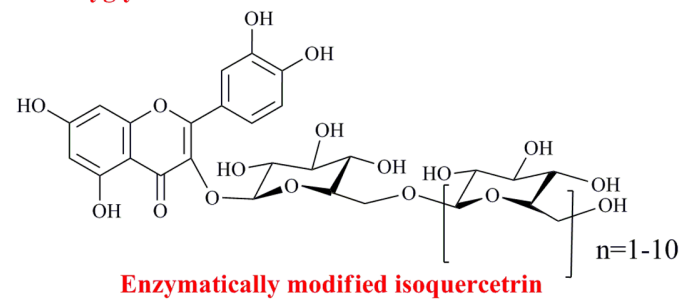
EMIQ 


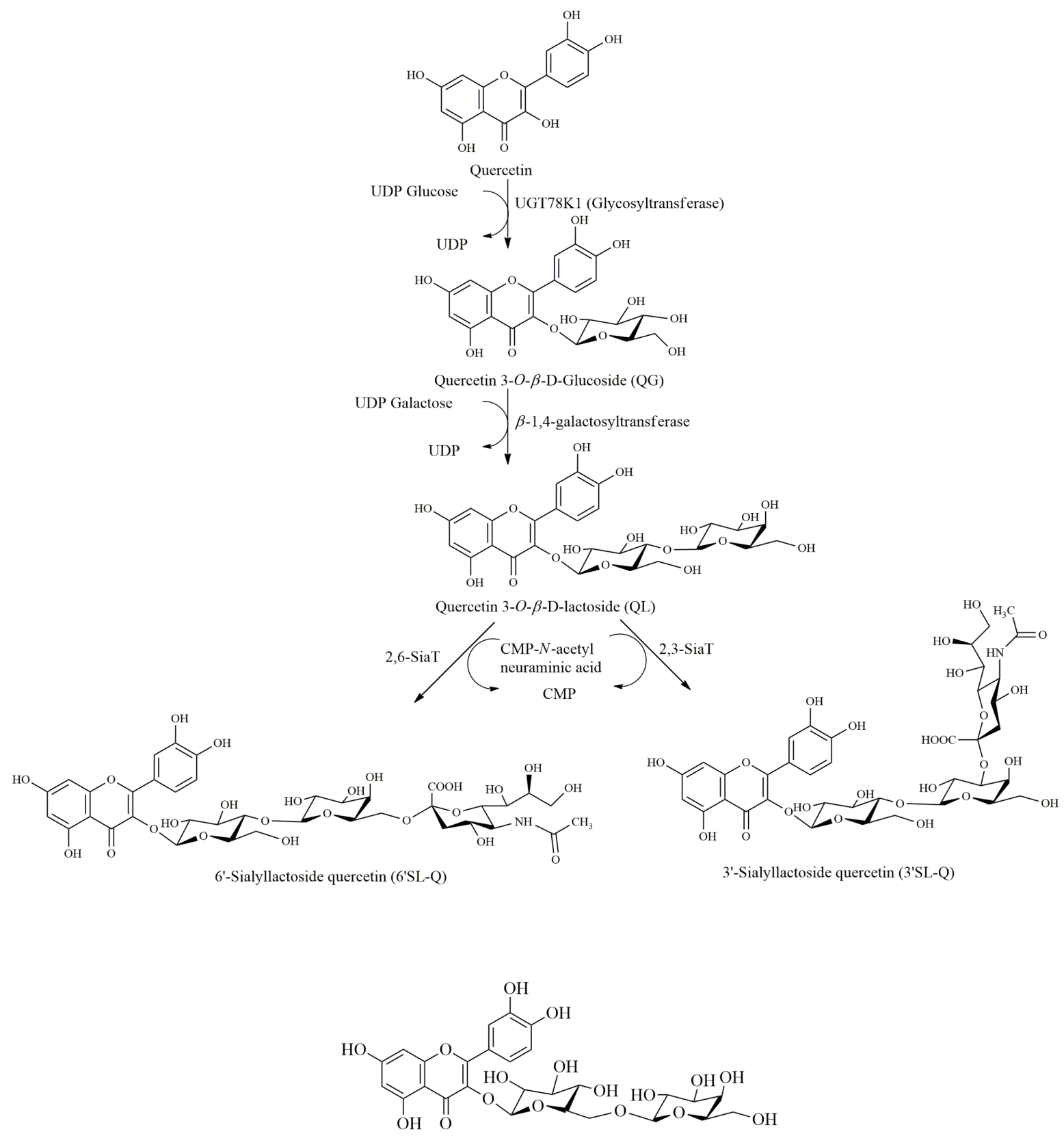

Fig. 2. Biosynthesis of quercetin sialyllactoside derivatives.

Two step reactions catalyzed by two glycosyltransferases (UGT78K1 and $\beta-(1,4)$-GalT) separately and sequentially produce quercetin 3-O-Dlactoside (QL) which then under the action of two sialyltransferase (2,3-SiaT and 2,6-SiaT) produce 3'-sialyllactosyl quercetin (3'-SL-Q) and 6'sialyllactosyl quercetin (6'-SL-Q) respectively.

conversion was found to be $95.20 \pm 2.52 \%$ and is more economical than is the conventional method.

Other enzymes, herperidinase from Penicillum sp. and naringinase from Penicillium decumbens, were used for the conversion of rutin to IQ by inactivating the undesirable $\beta$ D-glucosidase activity by heating to $70^{\circ} \mathrm{C}$ for $30 \mathrm{~min}$ [9].

Rutin to EMIQ: EMIQ is produced from rutin via a two- step reaction. At first step, $\alpha$-L-rhamnosidases activity leads to the derhamnosylation of rutin to produce isoquercetrin. Next step produces the enzymatically modified isoquercetrin under the action of cyclodextrin glucanotransferase (CGTase) [10]. Another enzyme, amylosucrase (ASase) from Deinococcus geothermalis, was also used by to convert isoquercetrin to EMIQ [11]. This enzyme uses sucrose 
Table 1. Some selected in vitro modification of quercetin.

\begin{tabular}{|c|c|c|c|}
\hline Quercetin conjugates & Biocatalysts used & Sources/activities of biocatalyst & References \\
\hline \multirow{3}{*}{$\begin{array}{l}\text { 3'-Sialyllactosyl quercetin } \\
\left(3^{\prime}-\text { SL-Q) and } 6^{\prime} \text {-sialyllactosyl }\right. \\
\text { quercetin }\left(6^{\prime}-\text { SL-Q) }\right.\end{array}$} & UGT78K1 (glycosyltransferase) & Glycine max/quercetin to quercetin 3-O- $\beta$-D-glucoside & 7 \\
\hline & $\beta$-1,4-galactosyltransferase & $\begin{array}{l}\text { Helicobacter pylori/conversion of quercetin 3-O- } \beta \text {-D- } \\
\text { glucoside to quercetin } 3-O-\beta \text {-D-lactoside }\end{array}$ & \\
\hline & $\begin{array}{l}\text { Sialyltransferases, } \alpha 2,3-\text { SiaT and } \\
\alpha 2,6-\text { SiaT }\end{array}$ & $\begin{array}{l}\text { Pasteurella multocida/ quercetin 3-O- } \beta \text {-D-lactoside to } 3^{\prime} \text { - } \\
\text { sialyllactosyl quercetin ( } 3^{\prime} \text {-SL-Q) and } 6^{\prime} \text {-sialyllactosyl } \\
\text { quercetin }\left(6^{\prime} \text {-SL-Q) respectively }\right.\end{array}$ & \\
\hline \multirow[t]{2}{*}{ Isoquercetrin (IQ) from rutin } & Naringinase & Penicillium decumbens/derhamnosylation of rutin & 8,9 \\
\hline & Hesperidinase & Penicillium sp./derhamnosylation of rutin & 9 \\
\hline \multirow[t]{2}{*}{ EMIQ from Isoquercetrin } & $\begin{array}{l}\text { Cyclodextrin glucosyltransferase } \\
\text { (CGTase) }\end{array}$ & Bacillus macerans/ oligoglucosylation of IQ & 10 \\
\hline & Amylosucrase (ASase) & Deinococcus geothermalis/oligoglucosylation of IQ & 11 \\
\hline
\end{tabular}

rather than dextrin as co- substrate. They found the conversion rate of $97 \%$ for ASase as compared to that of CGTase of only $75 \%$ (Table 1).

The transglycosylation of rutin is another type of modification, where rutin is oligoglycosylated without hydrolyzing the rhamnose sugar. As a result, oligosaccharides are attached to the glucoside group of rutin. The enzyme CGTase can do this with dextrin as a sugar group donor. The overall biosynthetic steps are summarized in Fig. 3.

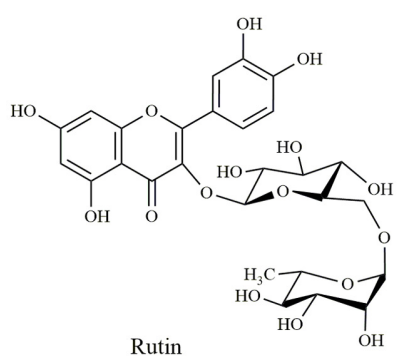<smiles>CC(C)(C)C</smiles>

Rutin

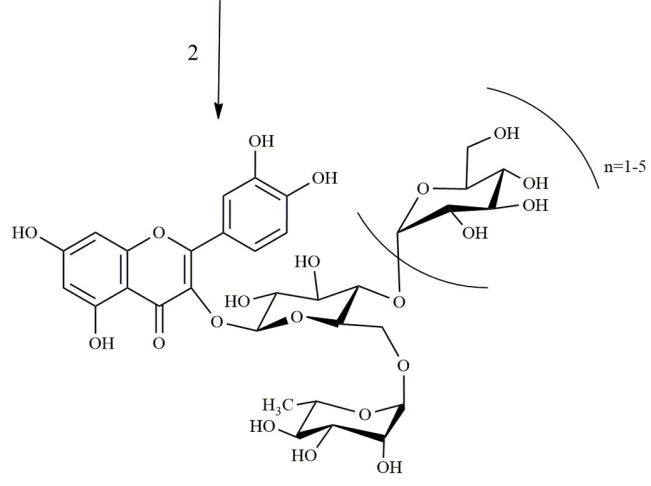

Oligoglucosylated rutin

\section{Metabolic Engineering of $E$. coli for Modification of Quercetin}

E. coli is engineered to express the desired biocatalysts isolated from various sources and deletion of unnecessary genes and overexpression of some other genes of E. coli are also performed in some cases. Then, this engineered E. coli is used for biotransformation of quercetin. The brief overview of this strategy is figuratively described in Fig. 4.

Glycosylation. Glycosylation of quercetin is the most studied modification strategy in the field of producing 


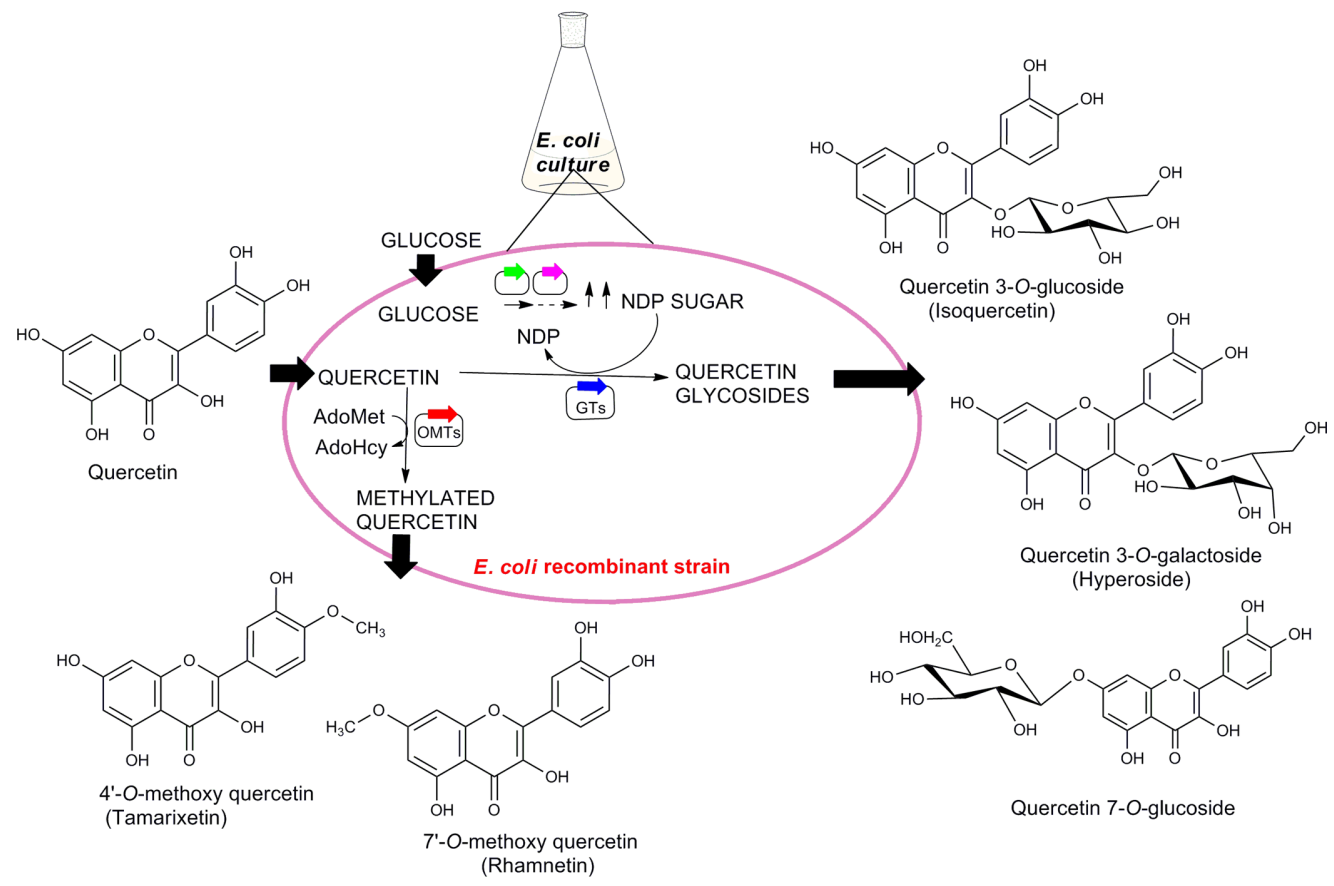

Fig. 4. Biotransformation in engineered E. coli.

Engineered E. coli produce glycosyltransferases (GTs) and nucleoside diphosphate sugar (NDP-sugar). The NDP-sugar is used by GTs for the formation of quercetin glycosides. On the other hand, O-methyl transferase (OMTs) uses S-adenosylmethionine (AdoMet) for methylation of quercetin releasing S-adenosylhomocysteine (AdoHcy).

glycosides derivatives. The glycosyltransferases (GTs) are biocatalysts that are overexpressed in E. coli that glycosylates quercetin to produce desired modification. The biosynthesis quercetin 3-O-glucoside is one of the few examples where E. coli is engineered to overexpress RF5 (Flavanol-3-O-glucosyltransferse) [12]. Here, the source of the former enzyme is Oryza sativa while for the latter is Bacillus cereus to enzyme is Oryza sativa.

In some cases, the required nucleoside diphosphate sugar (NDP sugar) is not synthesized in E. coli. Hence, in this case, respective genes for their synthesis and the required glycosyltransferase are overexpressed together. As a result, a novel quercetin glycoside with a different sugar is synthesized. One of the examples is a novel quercetin glycosides (quercetin 3-O-(6-deoxytalose) which was synthesized by using genes tll (encodes dTDP-6deoxy-L-lyxo-4-hexulose reductase) from Actinobacillus actinomycetemcomitans that convert dTDP-4-dehydro-6deoxy-L-mannose to dTDP-6-deoxytalose, and glycosyl transferase AtUGT78D1 (flavonol 3-O-rhamnosyltransferase) from Arabidopsis thaliana that produces quercetin 3-O-6deoxytalose [14]. Moreover, they also engineered the nucleoside diphosphate biosynthetic genes in E. coli for increased synthesis of dTDP-6-deoxytalose. They deleted some genes of the dTDP-L-rhamnose biosynthetic pathway, such as gall (UTP-glucose 1-phosphate uridyltransferase), rffA (dTDP-4-oxo-6-deoxy-D-glucose transaminase), rfbD (dTDP-4-dehydrorahmnose reductase), and overexpressed tll AtUGT78D1. This synthesized mutant produced $>6.5-$ fold higher quercetin 3-O-(6-deoxytalose) than did the wild type.

In other case, two glycosyltransferases are overexpressed in E. coli in order to generate the quercetin diglycosides. Example includes rutin which was synthesized at a concentration of about $119.8 \mathrm{mg} / 1$ from engineered $E$. coli in such a way that one UGT BcGT1 from Bacillus cereus was integrated into an E. coli chromosome, and other UGT (UGT, Fg2 from G. max) was expressed along with the rhamnose synthase gene (RHM2) [15]. Hence by optimization of the steps, they produced rutin from quercetin in a significant amount.

Similarly, a stepwise method for synthesis of quercetin diglycosides was also performed [16]. At first, they synthesized quercetin-3-O-glucoside (Q-G) and quercetin 3-O-arabinose (Q-A) from the engineered $E$. coli that contained genes for glycosyltransferase as well as for UDPglucuronic acid [17] and the UDP-arabinose synthetic pathway [18]. The next step was conversion to quercetin 
Table 2. Some selected glycosylation of quercetin in E. coli.

\begin{tabular}{|c|c|c|c|}
\hline Quercetin glycosides & Biocatalysts used in E. coli & Sources/activities of biocatalyst & References \\
\hline Quercetin 3-O-glucoside & RF5 (Flavanol-3-O-glucosyltransferse) & Oryza sativa/ glycosylation of quercetin & 12 \\
\hline \multirow[t]{6}{*}{ Quercetin 3-O-xyloside } & Phosphoglucomutase (nfa44530) & $\begin{array}{l}\text { Nocardia farcinica/ glucose } 6 \text { phosphate to glucose } 1 \\
\text { phosphate }\end{array}$ & 13 \\
\hline & Glucose-1-phosphate uridylyltransferase & E. coli $K-12 /$ glucose 1 phosphate to UDP glucose & \\
\hline & $(\mathrm{galU})$ & Micromonospora echinospora spp. Calichensis/UDP & \\
\hline & UDP-glucose dehydrogenase (calS8) and & glucose to UDP xylose & \\
\hline & UDP-glucuronic acid decarboxylase & & \\
\hline & arGt-3 (Glycosyltransferase) & $\begin{array}{l}\text { Arabidopsis thaliana/quercetin to quercetin 3-O- } \\
\text { xyloside. }\end{array}$ & \\
\hline \multirow[t]{2}{*}{ Quercetin 3-O-(6-deoxytalose) } & $\begin{array}{l}\text { tll gene (encoding dTDP-6-deoxy-L-lyxo-4- } \\
\text { hexulose reductase) }\end{array}$ & $\begin{array}{l}\text { Actinobacillus actinomycetemcomitans /Convert } \\
\text { dTDP-4-dehydro-6-deoxy-L-mannose to dTDP-6- } \\
\text { deoxytalose. }\end{array}$ & 14 \\
\hline & $\begin{array}{l}A t U G T 78 D 1 \text { (flavonol 3-O- } \\
\text { rhamnosyltransferase) }\end{array}$ & $\begin{array}{l}\text { Arabidopsis thaliana/Quercetin to quercetin 3-O-(6- } \\
\text { deoxytalose). }\end{array}$ & \\
\hline $\begin{array}{l}\text { Quercetin 3-O-glucosyl } \\
(1 \rightarrow 2) \text { xyloside }\end{array}$ & AtUGT78D2 and AtUGT79B1 & $\begin{array}{l}\text { Arabidopsis thaliana/ quercetin to quercetin 3-O- } \\
\text { glucoside and then to quercetin 3-O-glucosyl }(1 \rightarrow 2) \\
\text { xyloside. }\end{array}$ & 15 \\
\hline $\begin{array}{l}\text { Quercetin 3-O-glucosyl }(1 \rightarrow 6) \\
\text { rhamnoside (Rutin) }\end{array}$ & AtUGT78D2 and Fg2. & $\begin{array}{l}\text { Arabidopsis thaliana/ quercetin to quercetin 3-O- } \\
\text { glucoside and } G . \max \text { /to rutin. }\end{array}$ & \\
\hline Quercetin 3-O-glucuronic acid & AtUGT89C1 and rhamnose synthase gene & Arabidopsis thaliana/rhamnosylation of quercetin & 16 \\
\hline 7-O- rhamnoside [Q-GR] and & RHM (Rhamnose synthase) & & 17 \\
\hline $\begin{array}{l}\text { quercetin 3-O- arabinose 7-O- } \\
\text { rhamnoside [Q-AR] }\end{array}$ & & & 18 \\
\hline \multirow[t]{2}{*}{$\begin{array}{l}\text { Miquelianin (Quercetin 3- } \\
\text { glucuronide) }\end{array}$} & $\begin{array}{l}\text { UDP-glucuronic acid biosynthesis genes } \\
\text { along with glucokinase }\end{array}$ & & 19 \\
\hline & $\begin{array}{l}\text { Glycosyltransferase } V v G T 5 \text { (UDP- } \\
\text { glucuronic acid: flavonol 3-O } \\
\text { glucuronosyltransferase) }\end{array}$ & $\begin{array}{l}\text { Grapevine (Vitis vinifera)/Quercetin to quercetin 3- } \\
\text { glucuronide }\end{array}$ & \\
\hline
\end{tabular}

diglycosides, quercetin 3-O-glucuronic acid 7-O-rhamnoside [Q-GR] and quercetin 3-O-arabinose 7-O-rhamnoside [QAR] by using a strain harboring AtUGT89C1 and the rhamnose synthase gene RHM. In this way, they found the conversion rate to be $77.7 \%$ and $71.8 \%$ for Q-AR and Q-GR, respectively, starting from quercetin.

More recently, a synthetic approach for the biosynthesis of another derivatives of quercetin, miquelianin (Quercetin 3-O-glucuronide) was designed [19]. Quercetin was converted to miquelianin by the engineered $E$. coli strain harboring the genes for UDP-glucuronic acid biosynthesis along with glucokinase and grapevine (Vitis vinifera) glycosyltransferase VvGT5 (UDP-glucuronic acid: flavonol
3-O-glucuronosyltransferase). As a result, the conversion of quercetin to miquelianin was found to be $31 \%$ and production was $30 \mathrm{mg} / 1(62 \mu \mathrm{mol} / \mathrm{l})$.

This is how desired glycosylated derivatives of quercetin are produced in engineered E. coli. Table 2 summarizes the biosynthesis of some of the important quercetin glycosides and the respective glycosyltransferase used.

Methylation. Methylation is another important modification of quercetin. O-methyl transferases (OMTs) catalyzes the methylation of quercetin in presence of S-adenosylmethionine (AdoMet) which acts as methyl donor producing methylated quercetin and $S$ adenosylhomocysteine (AdoHcy) the methylation of

Table 3. Some selected methylation of quercetin in E. coli.

\begin{tabular}{lcl}
\multicolumn{1}{c}{ Methylated quercetin } & Biocatalysts used in E. coli & \multicolumn{1}{c}{ Sources/activities of biocatalyst } \\
\hline $\begin{array}{l}\text { 3'-Methylated and the 3', } 4^{\prime} \text {-dimethylated } \\
\text { quercetin }\end{array}$ & ROMT-9 and SOMT2 & $\begin{array}{l}\text { Rice and Glycine max } / \text { methylates 3' and 4' } \\
\text { OH of quercetin }\end{array}$ \\
$4^{\prime}$-O-Methyl-quercetin & GerMIII & $\begin{array}{l}\text { Streptomyces sp. KCTC 0041BP/methylates at } \\
4^{\prime} \text { OH of quercetin }\end{array}$ \\
\hline
\end{tabular}


Table 4. Some selected glycosylation of quercetin in other native bacterial strains.

\begin{tabular}{|c|c|c|}
\hline Quercetin glycosides & Microorganisms used for biotransformation & References \\
\hline Quercetin 3-O- $\beta$-D-glycoside & Gliocladium deliquescensNRRL 1086/quercetin to quercetin glycoside & 22 \\
\hline Quercetin $4^{\prime}-O-\beta$-glucuronide & \multirow[t]{4}{*}{ Streptomyces M52104/quercetin to quercetin glucuronides } & \multirow[t]{4}{*}{23} \\
\hline Quercetin 3-O- $\beta$-glucuronide & & \\
\hline Quercetin 7-O- $\beta$-glucuronide & & \\
\hline Quercetin 3'-O- $\beta$-glucuronide & & \\
\hline $\begin{array}{l}\text { Quercetin-7-O- } \beta-4^{\prime \prime} \text {-deoxy-hex- } 4^{\prime \prime}- \\
\text { enopyranosiduronic acid }\end{array}$ & $\begin{array}{l}\text { Streptomyces rimosus subsp. rimosus ATCC 10970/quercetin to Quercetin-7-O- } \beta-4^{\prime \prime} \text { - } \\
\text { deoxy-hex- } 4^{\prime \prime} \text {-enopyranosiduronic acid }\end{array}$ & 24 \\
\hline
\end{tabular}

quercetin. Quercetin was modified to 3'-methylated and 3', 4'-dimethylated quercetin using two methyltransferase ROMT-9 and SOMT2 from Rice and Glycine max respectively by overexpression in E. coli [20]. They found that more than $90 \%$ of quercetin was converted to dimethylated quercetin. Moreover, methyl transferases from bacterial origin, such as GerMIII from Streptomyces sp. KCTC 0041BP [21], has been used for the synthesis of 4'-Omethyl-quercetin (Table 3).

\section{Quercetin Modification with Other Native Microorganisms}

Some other microorganisms besides $E$. coli has been using for the modification of quercetin. Here, these microorganisms are not engineered to overexpress the glycosyltransferase and respective NDP-sugar biosynthesis gene. Instead, the wild type strain as such is used for modifications where the native enzymes do the desired biological reactions.

Glycosylation. Besides E. coli, other microorganisms significantly do the glycosylation of quercetin. An important derivative, isoquercetrin (quercetin-3-O- $\beta$-D-glucopyranoside), was produced in Gliocladium deliquescens NRRL 1086 after the bioconversion of quercetin [22]. Interestingly, microbial glucuronidation is another method for the generation of quercetin glycosides. Biotransformation of quercetin in the Streptomyces strain M52104 resulted in many glucuronides derivatives, such as quercetin $44^{\prime}-O$ - $\beta$-glucuronide $(50 \%)$, quercetin $3-O-\beta$-glucuronide, quercetin $7-O-\beta$-glucuronide (together $38 \%$ ), and quercetin $3^{\prime}-O-\beta$-glucuronide [23]. A novel quercetin glycoside, quercetin-7-O- $\beta-4^{\prime \prime}$-deoxy-hex- 4"'-enopyranosiduronic acid, was produced by biotransformation of quercetin in Streptomyces rimosus subsp. rimosus ATCC10970. The complete conversion was seen within three days of culture [24]. These are summarized in Table 4.

Methylation. Like glycosylation, different microorganisms have been used for synthesis of methylated quercetin. To name a few, Streptomyces griseus ATCC13273 was used for quercetin biotransformation which resulted in mono- and dimethoxy ring $\mathrm{B}$ metabolites 3'-O-methyl quercetin, and 3,5,7-trihydroxy-3', $4^{\prime}$-dimethoxyflavone [25]. B. bassiana ATCC7159 was used for 3'-O-methylquercetin and 3'-Omethylquercetin-7-glucuronide metabolites [26]. These are all summarized in Table 5.

Hydroxylation and sulfation. The modification of quercetin with a hydroxyl group has been studied less than glycosylation and methylation. In one study, myricetin $\left(3,5,7,3^{\prime}, 4^{\prime}, 5^{\prime}\right.$-hexahydroxyflavone) was produced by Streptomyces griseus, and the same strain also produced the plant flavonoid gossypetin $\left(3,5,7,8,3^{\prime}, 4^{\prime}\right.$-hexahydroxyflavone) after biotransformation of quercetin that showed the $4^{\prime}$ and 8-hydroxylation [25].

Sulfation is another type of modification found in quercetin. In one of the works, quercetin was successfully sulfated to quercetin 3'-O-sulfate via the biotransformation in Beauveria bassiana ATCC7159 [26]. They checked the biotransformation of quercetin not only in B. bassiana ATCC7159 but also in 10 isolates of Beauveria $s p$ strains isolated from soil samples of central Brazil. All of the strains successfully produced the sulfated quercetin.

Table 5. Some selected methylation of quercetin in other native bacterial strains.

\begin{tabular}{ll}
\hline \multicolumn{1}{c}{ Methylated quercetin } & \multicolumn{1}{c}{ Microorganisms used for biotransformation } \\
\hline 3'-O-Methyl quercetin, & Streptomyces griseus/quercetin to methylated conjugates \\
3,5,7-Trihydroxy-3', 4'-dimethoxyflavone & \\
3,5,7,3', 4'-Pentahydroxy-8-methoxyflavone (8-methoxyquercetin) & \\
3'-O-Methylquercetin & B. bassiana ATCC 7159/quercetin to methylated querce- \\
3'-O-Methylquercetin-7-glucuronide & tin and methylated quercetin glucuronides \\
\hline
\end{tabular}




\section{Structural Activity Relationship of Quercetin and Its Derivatives}

Studies of the biological activities of quercetin and its derivatives have concluded that they have different activities and efficacies because of modification at important positions of the quercetin molecule. The modification with glycosides usually occurs at the $3-\mathrm{OH}$ and $7-\mathrm{OH}$ positions, whereas methylations is usually preferred at the $3^{\prime}, 4^{\prime}$ and $7-\mathrm{OH}$ positions. In one of the works, the structure activity relationship of quercetin and its derivatives on antioxidant and anti-inflammatory activities was studied [27]. They have identified that modification of quercetin reduces its antioxidant activity. They found the overall activity as quercetin $>$ tamarixetin $=$ isorhamnetin $>$ quercetin-3-Oglucuronide>isorhamnetin-3-O-glucoside $>$ quercetin-3,5,7,3', $4^{\prime}$ penthamethylether > quercetin-3,4'-di-O-glucoside. These data said that the 3-hydroxyl group of quercetin plays an important role for antioxidant activity, and the mechanism was already described [28]. Similarly, the inhibition of lipid peroxidation was also studied, and the methylated quercetin metabolites tamarixetin and isorhamnetin have higher activity than does quercetin [27]. Their results were completely correlated with the study carried out previously [29].

The anti-inflammatory activity of monomethylated quercetin tamarixetin was highest among quercetin and its metabolites [27]. Hence they concluded that, unlike the antioxidant activity, the anti-inflammatory activity is not completely dependent on the number of free hydroxyl groups.

The anti-obesity effects of quercetin and quercetin 3glycosides have been studied and found that the latter has a higher effect than does the former [30], perhaps because better bioavailability results in better bioactivity, since the bioavailability of quercetin $3-\mathrm{O}$ glycosides is $235 \%$ higher than the $100 \%$ for quercetin $[30,28]$.

In conclusion, quercetin and its derivatives are important metabolites having various activities and efficacies. Moreover, a particular metabolite can have high biological activity and can be used pharmacologically. Hence for generation of active metabolites, modification of quercetin should be done. The important reactions are glycosylation, methylations, and hydroxylations. Glycosylation produces quercetin derivative with various sugar units at different hydroxyl groups, which creates not only the novel metabolites but also the increased activity and functions different from those of the parent. Hence, finding biocatalysts that could modify a parent molecule to novel analogues is of great interest to many researchers. Likewise, study of the structural activity relationship of quercetin and its derivatives also provides information for increasing the efficacy of the metabolites with decreasing toxicity. There is still some work to be done for understanding the change in activity of metabolites with the change in structure. This could provide an important field of research to some researchers as well.

\section{Acknowledgments}

This work was supported by a grant from the NextGeneration BioGreen 21 Program (SSAC, grant No. PJ013137), Rural Development Administration, Republic of Korea.

\section{Conflict of Interest}

The authors have no financial conflicts of interest to declare.

\section{References}

1. Nemeth K, Piskuła MK. 2007. Food content, processing, absorption and metabolism of onion flavonoids. Crit. Rev. Food Sci. Nutr. 47: 397-409.

2. Berardini N, Fezer R, Conrad J, Beifuss U, Carle R, Schieber A. 2005. Screening of mango (Mangifera indica L.) cultivars for their contents of flavonol O- and xanthone C-glycosides, anthocyanins and pectin. J. Agric. Food Chem. 53: 1563-1570.

3. Ramalho SD, de Sousa LR, Burger MC, Lima MI, da Silva MF, Fernandes JB, et al. 2015. Evaluation of flavonols and derivatives as human cathepsin B inhibitor. Nat. Prod. Res. 29: 2212-2214.

4. Qiu X, Kroeker A, He S, Kozak R, Audet J, Mbikay M, Chretien M. 2016. Prophylactic efficacy of quercetin 3- $\beta$-OD-glucoside against Ebola virus infection. Antimicrob. Agents Chemother. 60: 5182-5188.

5. Lee S, Sy S, Lee Y, Park Y, Kim BG, Ahn JH, et al. 2011. Rhamnetin production based on the rational design of the poplar O-methyltransferase enzyme and its biological activities. Bioorg. Med. Chem. Lett. 21: 3866-3870.

6. Makino T, Shimizu R, Kanemaru M, Suzuki Y, Moriwaki M, Mizukami H. 2009. Enzymatically modified isoquercitrin, alpha-oligoglucosyl quercetin 3-O-glucoside, is absorbed more easily than other quercetin glycosides or aglycone after oral administration in rats. Biol. Pharm. Bull. 32: 20342040.

7. Darsandhari S, Bae JY, Shrestha B,Yamaguchi T, Jung HJ, Han JM, et al. 2018. Enzymatic synthesis of novel quercetin sialyllactoside derivatives. Nat. Prod. Res. 6: 1-9. 
8. Lee YS, Huh JY, Nam SH, Kim D, Lee SB. 2013. Synthesis of quercetin-3-O-glucoside from rutin by Penicillium decumbens naringinase. J. Food Sci. 78: C411-415.

9. de Araújo ME, Moreira Franco YE, Alberto TG, Sobreiro MA, Conrado MA, Priolli DG, et al. 2012. Enzymatic deglycosylation of rutin improves its antioxidant and antiproliferative activities. Food Chem. 141: 266-273.

10. Lee YS, Woo JB, Ryu SI, Moon SK, Han NS, Lee SB. 2017. Glucosylation of flavonol and flavanones by Bacillus cyclodextrin glucosyltransferase to enhance their solubility and stability. Food Chem. 229: 75-83.

11. Rha CS, Choi JM, Jung YS, Kim ER, Ko MJ, Seo DH, et al. 2019. High-efficiency enzymatic production of $\alpha$ isoquercitrin glucosides by amylosucrase from Deinococcus geothermalis. Enzym. Microb. Technol. 120: 84-90.

12. Kim JH, Shin KH, Ko JH, Ahn JH. 2006. Glucosylation of flavonols by Escherichia coli expressing glucosyltransferase from rice (Oryza sativa). J. Biosci. Bioeng. 102: 135-137.

13. Pandey RP, Malla S, Simkhada D, Kim BG, Sohng JK. 2013. Production of 3-O-xylosyl quercetin in Escherichia coli. Appl. Microbiol. Biotechnol. 97: 1889-1901.

14. Yoon JA, Kim BG, Lee WJ, Lim Y, Chong Y, Ahn JH. 2002. Production of a novel quercetin glycoside through metabolic engineering of Escherichia coli. Appl. Environ. Microbiol. 78: 4256-4262.

15. An DG, Yang SM, Kim BG, Ahn JH. 2016. Biosynthesis of two quercetin O-diglycosides in Escherichia coli. J. Ind. Microbiol. Biotechnol. 43: 841-849.

16. Choi GS, Kim HJ, Kim EJ, Lee SJ, Lee Y, Ahn JH. 2018. Stepwise synthesis of quercetin bisglycosides using engineered Escherichia coli. J. Microbiol. Biotechnol. 28: 18591864.

17. Han SH, Kim BG, Yoon JA, Chong Y, Ahn JH. 2014. Synthesis of flavonoid O-pentosides by Escherichia coli through engineering of nucleotide sugar synthesis pathways and glycosyltransferase. Appl. Environ. Microbiol. 80: 27542762.

18. Kim SY, Lee HR, Park KS, Kim BG, Ahn JH. 2015. Metabolic engineering of Escherichia coli for the biosynthesis of flavonoid O-glucuronides and flavonoid O-galactoside. Appl. Microbiol. Biotechnol. 99: 2233-2242.
19. Pandey RP, Jung HY, Parajuli P, Nguyen THT, Bashyal P, Sohng JK. 2019. A synthetic approach for biosynthesis of miquelianin and scutellarin A in Escherichia coli. Appl. Sci. 9: 215.

20. Kim BG, Shin KH, Lee Y, Hur HG, Lim Y, Ahn JH. 2005. Multiple regiospecific methylations of a flavonoid by plant O-methyltransferases expressed in E. coli. Biotechnol. Lett. 27: 1861-1864.

21. Darsandhari S, Dhakal D, Shrestha B, Parajuli P, Seo JH, Kim TS, et al. 2018. Characterization of regioselective flavonoid O-methyltransferase from the Streptomyces $\mathrm{sp}$. KCTC 0041BP. Enzym. Microb. Technol. 113: 29-36.

22. Xu JQ, Fan N, Yu BY, Wang QQ, Zhang J. 2017. Biotransformation of quercetin by Gliocladium deliquescens NRRL 1086. Chin. J. Nat. Med. 15: 615-624.

23. Marvalina C, Azerada R. 2011. Microbial glucuronidation of polyphenols. J. Mol. Catal. B Enzym. 73: 43-52.

24. Ma B, Zeng J, Shao L, Zhan J. 2013. Efficient bioconversion of quercetin into a novel glycoside by Streptomyces rimosus subsp. rimosus ATCC 10970. J. Biosci. Bioeng. 115: 24-26.

25. Hosny M, Dhar K, Rosazza JPN. 2001. Hydroxylations and methylations of quercetin, fisetin, and catechin by Streptomyces griseus. J. Nat. Prod. 64: 462-465.

26. de MB Costa EM, Pimenta FC, Luz WC, de Oliveira V. 2008. Selection of filamentous fungi of the Beauveriagenus able to metabolize quercetin like mammalian cells. Braz. J. Microbiol. 39: 405-408.

27. Lesjak M, Beara I, Simin I, Pintać D, Majkić T, Bekvalac K, et al. 2018. Antioxidant and anti-inflammatory activities of quercetin and its derivatives. J. Funct. Foods. 40: 68-75.

28. Rice-Evans CA, Miller NJ, Paganga G. 1996. Structureantioxidant activity relationships of flavonoids and phenolic acids. Free Radic. Biol. Med. 20: 933-956.

29. Santos AC, Uyemura SA, Lopes JL, Bazon JN, Mingatto FE, Curti C. 1998. Effect of naturally occurring flavonoids on lipid peroxidation and membrane permeability transition in mitochondria. Free Radic. Biol. Med. 24: 1455-1461.

30. Lee CW, Seo JY, Lee J, Choi JW, Cho S, Bae JY, et al. 2017. 3-O-Glucosylation of quercetin enhances inhibitory effects on the adipocyte differentiation and lipogenesis. Biomed. Pharmacother. 95: 589-598. 